\title{
Effects of Mono- and Dual Blockade of the Renin-Angiotensin System on Markers of Cardiovascular Status in Hypertensive Patients with Mild and Moderate Renal Failure
}

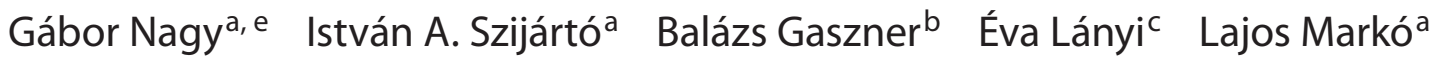 \\ Ákos Mérei $^{a} \quad$ Gergő A. Molnár ${ }^{a} \quad$ Kinga Németh ${ }^{d}$ József Betlehem ${ }^{\mathrm{e}}$ \\ István Wittmann ${ }^{a}$ \\ ${ }^{\mathrm{a}}$ 2nd Department of Medicine and Nephrological Center, ${ }^{\mathrm{b}}$ Heart Institute, Departments of ${ }^{\mathrm{c}}$ Laboratory Medicine \\ and ${ }^{d}$ Radiology, Faculty of Medicine, ${ }^{e}$ Department of Emergency Care, Faculty of Health Science, University of Pécs, \\ Pécs, Hungary
}

\section{Key Words}

Brain natriuretic peptide $\cdot$ Endogenous ouabain •

Immuno-unreactive urinary albumin • Renin-angiotensin system blockade $\cdot$ Renal failure $\cdot$ Subclinical organ damage

\begin{abstract}
Background/Aims: Dual renin-angiotensin system (RAS) blockade has no more efficiency to decrease cardiovascular mortality than mono-blockade. Our goal was to explore differences between other cardiovascular markers in patients with RAS blockade. Methods: We analyzed two groups of patients treated with a long-term ACE inhibitor (MONOgroup, $n=20$ ) and an ACE inhibitor and angiotensin II receptor blocker (DUAL-group, $n=15$ ). Ambulatory blood pressure monitoring, echocardiography, arterial stiffness and levels of catecholamine, endogenous ouabain (EO), pro-brain natriuretic peptide and more types of urinary albumin measurements were performed. Results: In the DUAL-group, we found significantly better cardiac parameters, but the levels of EO and urinary albumins were similar in both groups. The level of EO correlates with nighttime mean arterial blood pressure $(R=0.556, p=0.032)$ and arterial $\beta$-stiffness $(R=$
\end{abstract}

$0.512, p=0.042$ ). Urinary immuno-unreactive albumin showed a relationship with diastolic dysfunction of the heart $(R=-0.508, p=0.045)$ diurnal index of diastolic blood pressure $(R=-0.569, p=0.021)$ in the MONO-group. Conclusion: Cardiac parameters were more prosperous in the DUALgroup, but the levels of EO did not differ between groups. The level of EO correlated with blood pressure and arterial stiffness markers in the MONO-group only. The urinary immuno-unreactive albumin may be a new marker of cardiovascular conditions.

Copyright $\odot 2011$ S. Karger AG, Basel

\section{Introduction}

Hypertension is commonly associated with other conditions such as diabetes mellitus and chronic kidney disease (CKD), especially in elderly [1]. In the pathophysiological background of these diseases, the increased reninangiotensin system (RAS) activity plays a major role [2]. The treatment of these high-risk patients is complex, but the main goal is to reduce the grade of albuminuria and other clinical and subclinical organ damage [3]. Before

\section{KARGER}

Fax +4161306 1234 E-Mail karger@karger.ch www.karger.com
István Wittmann, $\mathrm{MD}, \mathrm{PhD}$

2nd Department of Medicine and Nephrological Center

Faculty of Medicine, University of Pécs

1 Pacsirta St., HU-7624 Pécs (Hungary)

Tel. +36 72536 050, E-Mail istvan.wittmann@aok.pte.hu 
the ONTARGET study, some studies proved that the dual blockade (angiotensin-converting enzyme inhibitor and angiotensin II receptor blocker) is better for reducing proteinuria and blood pressure in hypertensive patients with diabetes mellitus and albuminuria [4]. The dual blockade has an additive effect on reduction of left ventricular hypertrophy, arterial pulse wave velocity and plasma pro-brain natriuretic peptide (pro-BNP) level compared to the mono-RAS blockade in hypertensive patients with left ventricular hypertrophy [5].

The ONTARGET study in turn suggested that the long-term dual blockade worsens the renal outcome and does not decrease the mortality in patients with high cardiovascular risk $[6,7]$

Besides RAS activation, other pathophysiological abnormalities also play a role in the development of hypertension and CKD, such as increased sympathetic activation and increased levels of some endogenous vasoactive agents. Endogenous digitalis-like factors [e.g. endogenous ouabain (EO) and marinobufagenin], which are mainly formed in the adrenal cortex, have been linked to the pathophysiology of essential hypertension, congestive heart failure and end-stage renal failure [8]. Measurement of serum $\mathrm{N}$-amino terminal fragment of pro-BNP has frequently been used in the risk assessment of cardiovascular events and is known as a strong predictor of cardiovascular mortality and cardiovascular events [9].

CKD and diabetic nephropathy start with a low amount of excretion of albumin (microalbuminuria) and are associated with increased risks of cardiovascular morbidity and mortality [10-12]. Early and exact detection of urinary albumin is important in patients with hypertension, diabetes mellitus and CKD to determine the appropriate therapy $[13,14]$. Based on the different measurement methods, urinary albumin exists in immunoreactive and immunounreactive forms $[15,16]$. The recently developed highperformance liquid chromatography (HPLC) assay measures the total (immunoreactive plus immuno-unreactive) urinary albumin, whereas the conventional immunobased methods (radioimmunoassay, immunoturbidimetry, immunonephelometry) measure immunoreactive albumin only [11]. Some previously published studies have shown significant associations between the level of urinary immunoreactive albumin and markers of cardiovascular diseases, but there is little information about the level of urinary immuno-unreactive albumin [17].

Our goal was to compare the complex cardiovascular status (including more types of urinary albumin, urinary and plasma EO, urinary catecholamines, serum pro-BNP and some markers of cardiovascular status including the results of echocardiography, echo-tracking and blood pressure) of the hypertensive patients with mild and moderate renal failure treated with mono- or dual RAS blockade.

\section{Subjects and Methods}

\section{Participants}

In a cross-sectional clinical study, 35 adult hypertensive patients with mild and moderate renal failure were investigated. Retrospectively, these patients received either mono- or dual therapy for blockade of the RAS blockade. In the MONO-group, patients were treated with an ACE inhibitor $(n=20$; for more than 2 years); in the DUAL-group, patients were treated with an ACE inhibitor plus angiotensin II receptor blocker $(n=15$; for more than 2 years; table 1). Inclusion criteria were age above 50 years, hypertension and a diagnosis of mild or moderate renal failure. Agents of RAS inhibition were unchanged for at least 1 year. All patients were on a low-sodium diet and their therapies were controlled by the physicians in our outpatient clinic. We do not have any data on the extent of target-organ damage in the patients at the time of initiation of mono- or dual blockade, except for proteinuria.

The cause of the initiation of the dual blockade was persistent albuminuria in spite of the treatment with the maximal dose of an ACE inhibitor. The drug dosage of the patients was individually determined, and a minimal effective dose of the agents that normalized blood pressure and albuminuria was used. Side effects of different RAS blockades were not found in this population.

CKD patients were diagnosed with diabetic nephropathy and nephrosclerosis. Exclusion criteria were hyper/hypothyroidism, adrenal gland adenoma, malignancy, acute infection, atrial fibrillation and pacemaker therapy. All subjects were treated for hypertension and CKD and/or type 2 diabetes mellitus in our outpatient clinic, and had no symptoms of severe congestive heart failure. None of the subjects was taking cardiac glycoside, spironolactone, prednisolone or other steroids.

The study was approved by the Ethical Committee of the Medical Faculty of the University of Pécs and all participants gave their written informed consent before taking part in the study. The study was conducted in agreement with the Declaration of Helsinki.

The ambulatory blood pressure monitoring (ABPM) was performed with ABPM-04 (Meditech Ltd., Budapest, Hungary) based on a validated oscillometric technique. During the 24-hour monitoring period, the blood pressure was registered in $15-\mathrm{min}$ intervals in the daytime ( 8 a.m. to 10 p.m.) and 30 -min intervals at nighttime (10 p.m. to 8 a.m.). The hypertensive time index was expressed as a percentage of blood pressure values that exceeded the upper level of the normal range of blood pressure during daytime (systolic/diastolic: 140/90 $\mathrm{mm} \mathrm{Hg}$ ) and nighttime (systolic/ diastolic: 130/80 $\mathrm{mm} \mathrm{Hg}$ ). The results of blood pressure monitoring were analyzed by the proprietary software of ABPM-04.

Antihypertensive and insulin/antidiabetic therapies were not interrupted during the study.

There were no significant differences in serum sodium, potassium, chloride, calcium, liver enzymes (ALAT, ASAT, GGT, 
Table 1. Characteristics of MONO- and DUAL-group

\begin{tabular}{|c|c|c|}
\hline & MONO & DUAL \\
\hline Sex, male/female & $11 / 9$ & $5 / 10$ \\
\hline Age, years & $65.7 \pm 7.9$ & $60.8 \pm 6.9$ \\
\hline Duration of hypertension, years & $7.9 \pm 2.3$ & $6.1 \pm 3.1$ \\
\hline Duration of CKD, years & $3.0 \pm 1.3$ & $2.7 \pm 1.6$ \\
\hline Duration of diabetes mellitus, years & $4.0 \pm 1.6$ & $3.2 \pm 1.7$ \\
\hline Duration of RAS blockade before this study, years & $2.6,1.2-3.4$ & $2.4,1.1-3.2$ \\
\hline Type 2 diabetes mellitus, $\mathrm{n}(\%)$ & $7(35.5)$ & $7(46.6)$ \\
\hline$\beta$-Blocker, n (\%) & $13(65.0)$ & $6(40.0)$ \\
\hline Calcium channel blocker, n (\%) & $11(55.0)$ & $10(66.7)$ \\
\hline Diuretics, n (\%) & $10(50.0)$ & $8(53.3)$ \\
\hline Oral antidiabetics, $\mathrm{n}(\%)$ & $6(30.0)$ & $3(20.0)$ \\
\hline Insulin, $\mathrm{n}(\%)$ & $1(5.0)$ & $3(20.0)$ \\
\hline Oral antidiabetics plus insulin, $\mathrm{n}(\%)$ & $1(5.0)$ & $1(6.6)$ \\
\hline BMI & $28.1 \pm 4.1$ & $31.0 \pm 5.1$ \\
\hline $\mathrm{HbA}_{1 \mathrm{c}}, \%$ & $5.7 \pm 0.3$ & $6.3 \pm 0.9^{*}$ \\
\hline eGFR, MDRD ml/min $/ 1.73 \mathrm{~m}^{2}$ & $55.3 \pm 24.2$ & $62.6 \pm 20.6$ \\
\hline 24-hour urinary total albumin, $\mathrm{mg} / \mathrm{l}$ & $24.4,17.1-60.7$ & $24.11 \pm 9.9$ \\
\hline 24-hour urinary immunoreactive albumin, mg/l & $1.0,0.2-14.0$ & $1.0,0.0-3.0$ \\
\hline 24-hour urinary immuno-unreactive albumin, mg/l & $27.2 \pm 15.6$ & $21.1 \pm 9.1$ \\
\hline Ratio of total and immuno-unreactive urinary albumin, $\%$ & $75.4 \pm 32.5$ & $89.1 \pm 14.2$ \\
\hline Urinary norepinephrine, $\mathrm{nmol} / \mathrm{mmol}$ creatinine ${ }^{1}$ & $26.0 \pm 14.9$ & $24.9 \pm 14.7$ \\
\hline Urinary epinephrine, $\mathrm{nmol} / \mathrm{mmol}$ creatinine ${ }^{1}$ & $7.6 \pm 4.3$ & $6.2 \pm 1.8$ \\
\hline Urinary dopamin, $\mathrm{nmol} / \mathrm{mmol}$ creatinine $\mathrm{e}^{1}$ & $102.6 \pm 54.8$ & $128.2 \pm 53.1$ \\
\hline Plasma EO, pmol/l & $14.7 \pm 8.5$ & $14.6 \pm 6.1$ \\
\hline Urinary $\mathrm{EO}, \mathrm{pmol} / \mathrm{day}$ & $99.4 \pm 30.9$ & $102.4 \pm 46.4$ \\
\hline Pro-BNP, pg/ml & $176.2,90.5-373.8$ & $30.5,9.8-81.1^{*}$ \\
\hline Intima-media thickness, $\mathrm{mm}$ & $0.81 \pm 0.14$ & $0.70 \pm 0.23$ \\
\hline
\end{tabular}

Data are presented as means \pm standard deviation or as median and interquartile range; and frequency (\%) in cases of categorical variables. ${ }^{1}$ Measurement in morning urine. ${ }^{*} \mathrm{p}<0.05$ vs. MONO-group.

LDH), serum triglyceride, HDL, LDL cholesterol, C-reactive protein, or hematological parameters (red blood cell count, white blood cell, platelet) between groups (data not shown).

Patients' morning fresh urine was assessed by routine examination, including $\mathrm{pH}$, glucose, protein, pus, acetone, urobilinogen and creatinine, sodium, and potassium. Urinary creatinine was measured as a part of routine laboratory procedure by buffered kinetic Jaffe reaction (IDMS-calibrated) without deproteinization (Cobas Integra 400; Roche, Germany). The assessments of fresh urines did not show any abnormalities and there were no significant differences between groups in the results of routine fresh urinary examination (data not shown). The patients also collected 24-hour urine to measure the level of EO and microalbumin.

\section{Plasma and Urinary EO Determination}

All patients had a 6-ml morning blood draw from the cubital vein in EDTA tubes between 7:00 and 8:00 a.m. after being in a strict supine position for $40 \mathrm{~min}$. The blood samples were centrifuged at 3,000 $\mathrm{g}$ for $10 \mathrm{~min}$, and plasma was separated and transferred into plastic tubes and stored at $-20^{\circ} \mathrm{C}$ until assayed. Tenmilliliter urinary samples were taken out of the 24 -hour collected urine and stored at $-20^{\circ} \mathrm{C}$. The plasma and urinary samples were assayed after collecting all samples; the average storage period was 2 months. Plasma and urinary EO levels were determined by radioimmunoassay with Ouabain ${ }^{125}$ I RIA kit (Biotop OY, Medipolis Center, Oulu, Finland), as previously described [18]. All samples were measured in duplicate.

Urinary Catecholamine and Serum pro-BNP Measurements

The morning urinary catecholamines (epinephrine, norepinephrine and dopamine) were measured by the Bio-Rad Clinical HPLC System (Bio-Rad Laboratories Inc., France). Briefly, the acidified urinary samples were prepared by Analytical MicroGuard $^{\mathrm{TM}}$ Cartridges and $20 \mu$ l of prepared samples were analyzed by HPLC with the Model 1340C Electrochemical Detector (at 0.55 $\mathrm{mV}$ ). Urinary catecholamines/creatinine (assessed by Jaffe methods) ratios were calculated.

Serum pro-BNP levels were measured on a fully automated (Elecsys $^{\text {TM }}$ 2010) system (Roche Diagnostics, Mannheim, Germany), which is an electrochemiluminescent sandwich immunoassay using two polyclonal antibodies directed at the NTpBNP molecule. The intra-assay and interassay variabilities were $1.3-4.2$ and $1.8-4.6 \%$, respectively [19]. 
Urinary Microalbumin Measurements

The 24-hour urine samples were vortexed and centrifuged (10 $\min , 2,500 \mathrm{~g}$ ). Supernatants were divided into two portions. One portion was used to detect urinary albumin concentration by immunoturbidimetry using a Roche/Hitachi 812 Modular P Analyser (sensitivity: $3 \mathrm{mg} / \mathrm{l}$, intra-assay precision: 1.3 and $1.7 \%$, inter-assay precision 4.3 and $2.6 \%$, respectively, linearity: 3-3,000 mg/l; Roche Diagnostics GmbH, Mannheim, Germany). The other portion was used for HPLC analysis straightaway or in a few days (after storage at $-20^{\circ} \mathrm{C}$ ). For HPLC measurements, the FDA-approved Accumin ${ }^{\mathrm{TM}}$ kit [Accumin Diagnostics Inc., New York, N.Y., USA; sensitivity (quantitation limit): $3 \mathrm{mg} / \mathrm{l}$, linearity: $3-2,000 \mathrm{mg} / \mathrm{l}$, interassay and intra-assay precision (percentage coefficient of variation): 5.8 and $2.5 \%$ respectively], was used.

The amount of immuno-unreactive albumin was calculated as the difference between HPLC and immunoturbidimetry measured urinary albumin. In this study, we did not calculate with the albumin/creatinine ratio because the concentration of albumin was measured from 24 -hour collected urine.

\section{Echocardiography and Echo-Tracking Examination}

Echocardiograms were recorded with an Aloka SSD 5500 (Aloka Co. Ltd., Tokyo, Japan) ultrasound imaging system equipped with a $3.5-\mathrm{MHz}$ transducer. All patients were assessed by the same cardiologist and examined within $1 \mathrm{~h}$ (between 7:30 and $8.30 \mathrm{a} . \mathrm{m}$.) after the collection of EO samples and ABPM. Before echocardiography and echo-tracking, all patients were in a supine position for at least for $5 \mathrm{~min}$. Operators were blinded to the status of the patients. Left ventricle (LV) internal diameter, septal and posterior wall thickness were measured at end-diastole and end-systole, according to the American Society of Echocardiography guidelines [20]. Left ventricular mass was calculated at end-diastole by using the Devereux correction according to the American Society of Echocardiography cube left ventricular formula. Individual values for LV mass were indexed by body surface area. LV end-diastolic and end-systolic volumes were obtained by using the Teicholz formula. Stroke volume was calculated as the difference between end-diastolic and end-systolic volumes. The ejection fraction was calculated as the ratio of stroke volume to LV end-diastolic volume. Individual values were indexed by body surface area. The stroke index was multiplied by the heart rate to obtain the cardiac index. Blood pressure was recorded at the time of echocardiography. LV diastolic dysfunction was defined using transmitral Doppler parameters. Transmitral Doppler peak early diastolic E-wave velocity $(\mathrm{cm} / \mathrm{s})$, peak late A-wave diastolic velocity $(\mathrm{cm} / \mathrm{s})$, E/A ratio and deceleration time $(\mathrm{ms})$ were recorded [20]. The atrial areas $\left(\mathrm{mm}^{2}\right)$ were measured by the product of two atrial diameters.

Arterial stiffness parameters as the $\beta$-stiffness index, pulse wave velocity and augmentation index were assessed by the characteristics of pulse wave intensity using an echo-tracking system (Aloka SSD-5500) with a $10-\mathrm{MHz}$ linear array probe. We used the right common carotid arterial diameter change waveforms to obtain pressure waveforms noninvasively. The peak and bottom values of a diameter change waveform were calibrated using systolic and diastolic pressure measured with a cuff-type manometer applied to the upper arm, and the diameter change waveform was used as a blood pressure waveform [21].

RAS Blockade and Organ Damage
Intima-Media Thickness Measurement

Intima-media thickness was measured in the supine position by a real-time ultrasound scanner equipped with a $10-\mathrm{MHz}$ linear transducer (ALOKA SSD 4000). The measurement of intima-media thickness was done in $\mathrm{B}$ mode on the carotid artery under the bifurcation of the carotid artery in an anterolateral longitudinal view.

\section{Statistical Analyses}

The data are expressed as mean values \pm standard deviation, or as median values and interquartile range depending on the distribution. Distribution of the variables was analyzed using a Kolmogorov-Smirnov test. Normally distributed variables were compared using a two-sample test, while non-normal distributed variables were compared with a Mann-Whitney U test. Parameter differences between the groups were analyzed with a univariate general linear model, adjusted for $\mathrm{HbA}_{1 \mathrm{c}}$, LVESD, LVESV and ejection fraction of the heart. Noncontinuous parameters were analyzed by a $\chi^{2}$ test. The correlations between variables were analyzed using Pearson's (in cases of normally distributed variables) and Spearman's (non-normally distributed variables) correlations. The statistical analyses were performed using SPSS 13.0 (SPSS Inc., Chicago, Ill., USA) and two-tailed $\mathrm{p}<0.05$ was considered statistically significant.

\section{Results}

The main characteristics of the MONO- and DUALgroups are presented in table 1 . The level of pro-BNP was significantly higher in the MONO-group and $\mathrm{HbA}_{1 \mathrm{c}}$ in the DUAL-group, but after adjusting for parameters which were significantly different between the two groups $\left(\mathrm{HbA}_{1 \mathrm{c}}, \mathrm{LVESD}, \mathrm{LVESV}\right.$ and ejection fraction), the difference was not significant. After adjusting for $\mathrm{HbA}_{1 \mathrm{c}}$ only, the level of pro-BNP remained significant $(\mathrm{p}=0.045)$.

The level of pro-BNP correlated with almost all parameters of echocardiography listed in table $2(\mathrm{R}=0.341-$ 0.524 ) in both groups (data not shown).

Sodium and the potassium/creatinine ratio were measured in the morning fresh urine, but no differences between the groups were found $(\mathrm{p}>0.05)$.

The cardiovascular parameters of the two groups are shown in table 2.

We found no differences between the two groups regarding blood pressure and arterial stiffness parameters. The parameters of echocardiography showed some differences, but after adjusting for $\mathrm{HbA}_{1 c}$, only the ejection fraction remained significantly higher in the DUALgroup than in the MONO-group.

\section{Endogenous Ouabain}

We also wanted to analyze the correlation of levels of EO and urinary immuno-unreactive albumin, which 
Table 2. Cardiovascular parameters of MONO- and DUAL-group

\begin{tabular}{|c|c|c|}
\hline Parameter & MONO & DUAL \\
\hline \multicolumn{3}{|l|}{$A B P M, m m H G$} \\
\hline \multicolumn{3}{|l|}{ 24-hour mean } \\
\hline Systolic blood pressure & $127.2 \pm 15.0$ & $130.4 \pm 19.9$ \\
\hline Diastolic blood pressure & $70.5 \pm 9.4$ & $73.6 \pm 8.5$ \\
\hline Arterial blood pressure & $88.7 \pm 10.3$ & $92.2 \pm 11.6$ \\
\hline Pulse pressure & $56.5 \pm 10.3$ & $56.0 \pm 13.0$ \\
\hline \multicolumn{3}{|l|}{ Daytime mean } \\
\hline Systolic blood pressure & $129.3 \pm 14.6$ & $132.3 \pm 19.2$ \\
\hline Diastolic blood pressure & $73.1 \pm 9.6$ & $77.0 \pm 8.8$ \\
\hline Arterial blood pressure & $91.8 \pm 10.0$ & $95.5 \pm 11.5$ \\
\hline Pulse pressure & $55.8 \pm 10.7$ & $54.7 \pm 12.6$ \\
\hline \multicolumn{3}{|l|}{ Nighttime mean } \\
\hline Systolic blood pressure & $120.8 \pm 13.9$ & $127.4 \pm 22.5$ \\
\hline Diastolic blood pressure & $63.8 \pm 8.4$ & $68.1 \pm 8.8$ \\
\hline Arterial blood pressure & $82.5 \pm 9.4$ & $87.7 \pm 12.5$ \\
\hline Pulse pressure & $56.6 \pm 10.5$ & $59.0 \pm 16.4$ \\
\hline \multicolumn{3}{|l|}{ Echocardiography } \\
\hline LVESD, $\mathrm{mm}$ & $32.7 \pm 5.2$ & $29.2 \pm 3.2^{\mathrm{a}}$ \\
\hline LVEDD, mm & $48.7 \pm 5.3$ & $46.7 \pm 3.6$ \\
\hline LVESV, ml & $39.5 \pm 19.9$ & $27.1 \pm 8.9^{\mathrm{a}}$ \\
\hline LVEDV, ml & $125.1 \pm 41.7$ & $108.7 \pm 25.5$ \\
\hline LVEDVI, $\mathrm{ml} / \mathrm{m}^{2}$ & $67.0 \pm 20.5$ & $57.4 \pm 13.6$ \\
\hline LVMI, $\mathrm{g} / \mathrm{m}^{2}$ & $153.6 \pm 47.4$ & $138.8 \pm 24.7$ \\
\hline Ejection fraction, $\%$ & $56.6 \pm 4.5$ & $60.6 \pm 4.3^{\mathrm{a}, *}$ \\
\hline $\mathrm{E} / \mathrm{A}$ & $0.87 \pm 0.34$ & $0.91 \pm 0.30$ \\
\hline $\mathrm{SI}, \mathrm{ml} / \mathrm{m}^{2}$ & $45.8 \pm 11.8$ & $43.1 \pm 10.4$ \\
\hline $\mathrm{CI}, 1 / \mathrm{min} / \mathrm{m}^{2}$ & $3.14 \pm 0.88$ & $2.95 \pm 0.54$ \\
\hline \multicolumn{3}{|l|}{ Echo-tracking } \\
\hline Carotid PWV, $\mathrm{m} / \mathrm{s}$ & $7.3 \pm 1.6$ & $6.9 \pm 1.4$ \\
\hline Carotid Aix, \% & $23.7 \pm 12.3$ & $16.4 \pm 9.4$ \\
\hline Carotid $\beta$-stiffness & $13.0 \pm 8.6$ & $10.8 \pm 4.0$ \\
\hline \multicolumn{3}{|c|}{ 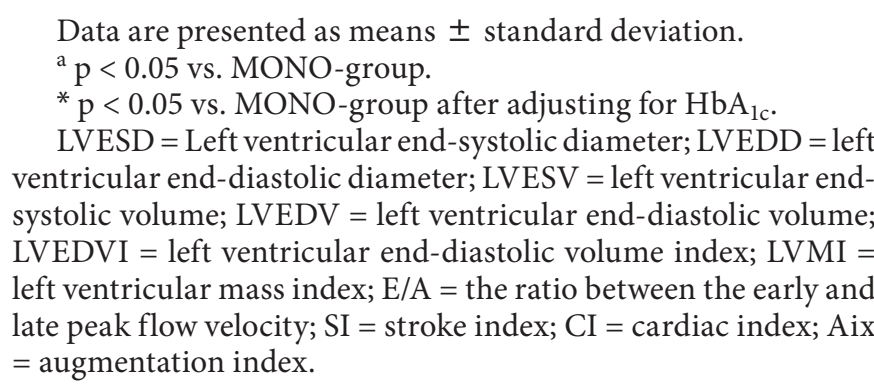 } \\
\hline
\end{tabular}

were not investigated previously in the context of monoand dual RAS blockade in hypertensives.

The level of plasma EO correlated with nighttime systolic $(\mathrm{R}=0.512, \mathrm{p}=0.046)$, mean arterial blood pressure $(\mathrm{R}=0.541, \mathrm{p}=0.038)$ and nighttime hypertensive time index of mean arterial pressure (fig. 1a), and urinary EO was associated with arterial stiffness parameters, such as carotid artery pulse wave velocity $(\mathrm{R}=0.621, \mathrm{p}=0.005)$ and $\beta$-stiffness (fig. $1 \mathrm{~b}$ ) in the MONO-group. These correlations were not found in the DUAL-group.

\section{Urinary Albumins}

Urinary immunoreactive albumin did not show any relationship with cardiovascular parameters or hormones in either the MONO- or DUAL-group. In the MONO-group, total urinary albumin was significantly associated with some blood pressure parameters, such as the 24-hour and daytime hypertensive time index of diastolic blood pressure $(\mathrm{R}=0.611, \mathrm{p}=0.034$ and $\mathrm{R}=0.654$, $\mathrm{p}=0.026$, respectively) and diastolic dysfunction (E/A) of the heart $(\mathrm{R}=-0.467, \mathrm{p}=0.049)$. Immuno-unreactive albumin strongly correlated with diastolic dysfunction (E/A) of the heart and the diurnal index of diastolic blood pressure (fig. 2). In the DUAL-group, total urinary albumin and immuno-unreactive albumin correlated only with the plasma level of EO (fig. 3).

\section{Discussion}

Our first main finding was that numerous markers/ parameters of the cardiovascular system did not show any difference between long-term mono- and dual RAS blockade in hypertensive patients with comorbidities. These results are in agreement with the previous results of the ONTARGET study [6]. On the other hand, left ventricular diameters and function (ejection fraction) were significantly better in the DUAL-group than in the MONOgroup, and the level of pro-BNP was significantly lower in the DUAL-group, which also shows an improved cardiac prognosis. The difference of levels in pro-BNP remained significant after adjusting for $\mathrm{HbA}_{1 c}$, but ceased after adjusting for $\mathrm{HbA}_{1 \mathrm{c}}$ and cardiac parameters. The association of the level of pro-BNP with parameters of echocardiography and the differences between the groups underline the hypothesis that the main cause of the level difference of pro-BNP may be the altered cardiac conditions.

The differences between echocardiographic parameters could not be explained by different sympathetic activity and its suppressions because the excreted levels of catecholamine and $\beta$-blocker therapy were similar.

The levels of plasma and urinary EO were similar in the two groups. Our level of plasma EO was similar to the one of the other study using the same method [18].

It is known that the production of $\mathrm{EO}$ can be decreased by an ACE inhibitor [8], but there are no data on the effect of dual blockade. According to the results of this cross- 
Fig. 1. Correlations between plasma EO and nighttime hypertensive time index of mean arterial blood pressure (MAP) (a) as well as between urinary EO and carotid artery $\beta$-stiffness (b) in the MONO-group.
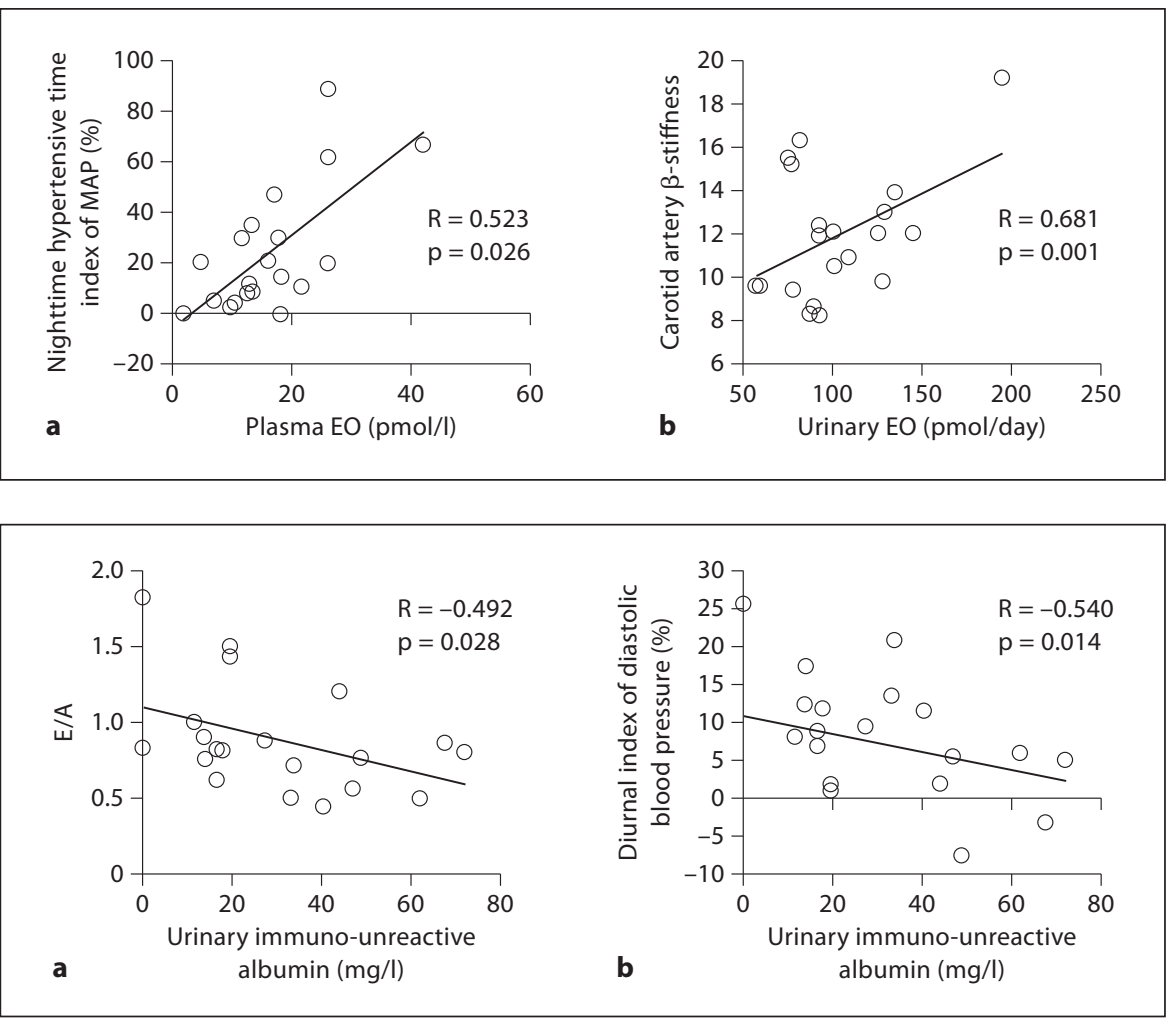
muno-unreactive albumin and $\mathrm{E} / \mathrm{A}$ (a) and diurnal index of diastolic blood pressure (b) in the MONO-group.

Fig. 3. Significant correlations between plasma EO level and urinary total (a) and immuno-unreactive albumin (b) in the DUAL-group.
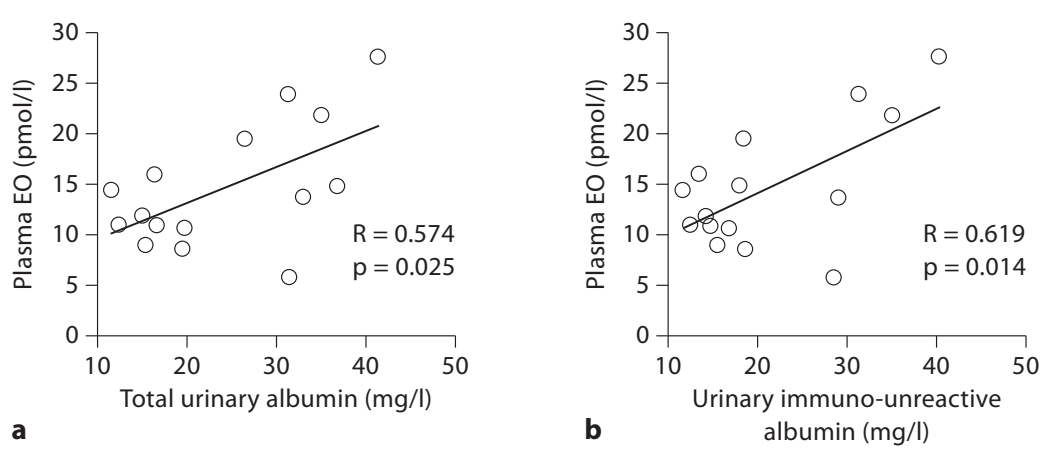

sectional study, the level of EO was not lower with dual blockade compared to the MONO-group.

In the MONO-group, the levels of EO correlated with blood pressure and arterial stiffness but, with the exception of albuminuria, we have not found associations with the levels of EO in the DUAL-group. A previous study did not find an association between the endogenous digitalislike substance and immunoreactive albumin excretion in hypertensive diabetic patients [22].

EO blockage of the sodium/potassium pump $\left(\mathrm{Na}^{+} / \mathrm{K}^{+}-\right.$ ATPase) consecutively increases the intracellular calcium level through the activation of the sodium-calcium exchanger, which produces vasoconstriction and enhances heart contraction. In addition to this classical effect, EO binds to $\mathrm{Na}^{+} / \mathrm{K}^{+}$-ATPase, which initiates several intracellular pathways, leading to myocardial and vascular smooth muscle cell hypertrophy [8]. EO also causes collagen overproduction by increased fibroblast activity in the heart muscle [23].

Our observation may suggest that although the dual blockade did not lead to lower levels of EO, it may decrease the intracellular pathway activity which leads to ventricular remodeling. In our opinion, dual blockade has a long-term effect on cardiac remodeling, which is 
underlined by better cardiac parameters of echocardiography.

Our other main findings were that the level of urinary albumin was higher when assessed by HPLC than immunoturbidimetry, and the cardiovascular parameters (blood pressure parameters, diastolic dysfunction of the heart) correlated with the grade of albuminuria determined by HPLC in the MONO-group. In the DUALgroup, however, EO was the only one which correlated with the urinary total and immune-unreactive albumins. None of these parameters correlated with immunoreactive urinary albumin.

In our study, the urinary level of albumin was in the near-normal albuminuric range, which shows that the therapy was appropriate and the greater part of total excreted urinary albumin remained immuno-unreactive. The exact nature and formation of immuno-unreactive albumin is not known. A study proposed that the immuno-unreactive albumin contain modified/split albumin, which is held together by noncovalent intrachain bridges $[15,24]$. A particular analysis of the immuno-unreactive albumin was made by Nakayama et al. [25] who detected that the main component of this fraction was modified albumin and contained a small amount of transferrin and other molecules in patients with cardiovascular disease.

It is also known that the reabsorbed albumin is degraded in the tubular cells of the kidneys and that the peptides of degradation are excreted to both the apical and basolateral sides of the cells and appear in the urine [26]. According to our previous results, as well as those of others, less than $15 \%$ of the proteins in HPLC albumin peak may be not albumin $[25,27]$. Our correlations with urinary immuno-unreactive albumin, but not with immunreactive albumin (which is frequently used by physicians) suggest that the examination of this fraction of urinary albumin may be better in clinical practice.

The limitations of our study are its cross-sectional nature and that we did not have the complete basal data of the patients.

In summary, we found that dual blockade of RAS compared to the mono-blockade in multimorbid patients with low albuminuria resulted in similar cardiovascular conditions, except for some echocardiographic parameters and pro-BNP. The level of EO, a new marker of cardiovascular status, did not differ between the two groups and it had correlations with nighttime blood pressure and arterial stiffness in the MONO-group only.

\section{Disclosure Statement}

The manuscript has been seen and approved by all authors and is not under consideration for publication elsewhere in a similar form, in any language, except in abstract form.

\section{References}

1 Bell DS: Hypertension and diabetes: a toxic combination. Endocr Pract 2008;14:10311039.

-2 Azizi M, Ménard J: Combined blockade of the renin-angiotensin system with angiotensin-converting enzyme inhibitors and angiotensin II type 1 receptor antagonists. Circulation 2004;109:2492-2499.

-3 Weir MR: Effects of renin-angiotensin system inhibition on end-organ protection: can we do better? Clin Ther 2007;29:1803-1824.

4 Sengul AM, Altuntas Y, Kürklü A, Aydin L: Beneficial effect of lisinopril plus telmisartan in patients with type 2 diabetes, microalbuminuria and hypertension. Diabetes Res Clin Pract 2006;71:210-219.

5 Anan F, Takahashi N, Ooie T, Yufu K, Hara M, Nakagawa M, Yonemochi H, Saikawa T, Yoshimatsu $\mathrm{H}$ : Effects of valsartan and perindopril combination therapy on left ventricular hypertrophy and aortic arterial stiffness in patients with essential hypertension. Eur J Clin Pharmacol 2005;61:353-359.
-6 ONTARGET Investigators, Yusuf S, Teo KK, Pogue J, Dyal L, Copland I, Schumacher H, Dagenais G, Sleight P, Anderson C: Telmisartan, ramipril, or both in patients at high risk for vascular events. N Engl J Med 2008; 358:1547-1559.

7 Mann JF, Schmieder RE, McQueen M, Dyal L, Schumacher H, Pogue J, Wang X, Maggioni $\mathrm{A}$, Budaj $\mathrm{A}$, Chaithiraphan S, Dickstein K, Keltai M, Metsärinne K, Oto A, Parkhomenko A, Piegas LS, Svendsen TL, Teo KK, Yusuf S, ONTARGET Investigators: Renal outcomes with telmisartan, ramipril, or both, in people at high vascular risk (the ONTARGET study): a multicentre, randomised, double-blind, controlled trial. Lancet 2008; 372:547-553.

-8 Bagrov AY, Shapiro JI. Endogenous digitalis: pathophysiologic roles and therapeutic applications. Nat Clin Pract Nephrol 2008;4: 378-392.
9 Kistorp C, Raymond I, Pedersen F, Gustafsson F, Faber J, Hildebrandt P: N-terminal pro-brain natriuretic peptide, C-reactive protein, and urinary albumin levels as predictors of mortality and cardiovascular events in older adults. JAMA 2005;293:16091616.

$>10$ Orea-Tejeda A, Colín-Ramírez E, Hernández-Gilsoul T, Castillo-Martínez L, AbastaJiménez M, Asensio-Lafuente E, Narváez David R, Dorantes-García J: Microalbuminuria in systolic and diastolic chronic heart failure patients. Cardiol J 2008;15: 143-149.

11 Polkinghorne KR, Su Q, Chadban SJ, Shaw JE, Zimmet PZ, Atkins RC: Population prevalence of albuminuria in the Australian Diabetes, Obesity, and Lifestyle (AusDiab) study: immunonephelometry compared with high-performance liquid chromatography. Am J Kidney Dis 2006;47:604-613. 
12 Jager A, Kostense PJ, Ruhé HG, Heine RJ, Nijpels G, Dekker JM, Bouter LM, Stehouwer CD: Microalbuminuria and peripheral arterial disease are independent predictors of cardiovascular and all-cause mortality, especially among hypertensive subjects: fiveyear follow-up of the Hoorn Study. Arterioscler Thromb Vasc Biol 1999;19:617-624.

-13 Deckert T, Kofoed-Enevoldsen A, Nørgaard K, Borch-Johnsen K, Feldt-Rasmussen B, Jensen T: Microalbuminuria. Implications for micro- and macro-vascular disease. Diabetes Care 1992;15:1181-1191.

-14 Pontremoli R, Sofia A, Ravera M, Nicolella C, Viazzi F, Tirotta A, Ruello N, Tomolillo C, Castello C, Grillo G, Sacchi G, Deferrari G: Prevalence and clinical correlates of microalbuminuria in essential hypertension. The MAGIC study. A Genoa investigation on complications. Hypertension 1997;30:11351143.

-15 Osicka TM, Comper WD: Characterization of immunochemically nonreactive urinary albumin. Clin Chem 2004;50:2286-2291.

16 Clavant SP, Sastra SA, Osicka TM, Comper WD: The analysis of immuno-unreactive urinary albumin in healthy volunteers. Clin Biochem 2006;39:143-151.
17 Weir MR: Microalbuminuria and cardiovascular disease. Clin J Am Soc Nephrol 2007;2 581-590.

18 Vakkuri O, Arnason SS, Joensuu P, Jalonen J, Vuolteenaho O, Leppäluoto J: Radioiodinated tyrosyl-ouabain and measurement of a circulating ouabain-like compound. Clin Chem 2001;47:95-101.

19 Collinson PO, Barnes SC, Gaze DC, Galasko G, Lahiri A, Senior R: Analytical performance of the $\mathrm{N}$ terminal pro $\mathrm{B}$ type natriuretic peptide (NT-proBNP) assay on the Elecsys 1010 and 2010 analysers. Eur J Heart Fail 2004;6:365-368.

20 Gottdiener JS, Bednarz J, Devereux R, Gardin J, Klein A, Manning WJ, Morehead A, Kitzman D, Oh J, Quinones M, Schiller NB, Stein JH, Weissman NJ, American Society of Echocardiography: American Society of Echocardiography recommendations for use of echocardiography in clinical trials. J Am Soc Echocardiogr 2004; 17:1086-1119.

21 Niki K, Sugawara M, Chang D, Harada A, Okada T, Sakai R, Uchida K, Tanaka R, Mumford CE: A new noninvasive measurement system for wave intensity: evaluation of carotid arterial wave intensity and reproducibility. Heart Vessels 2002;17:12-21.

22 Okamoto S, Ikeda M, Morise T, Miyamori I, Takeda R: Elevated endogenous digitalislike substance in hypertensive diabetic patients with a family history of hypertension. J Endocrinol Invest 1991;14:357-360.
23 Skoumal R, Szokodi I, Aro J, Földes G, Göoz M, Seres L, Sármán B, Lakó-Futó Z, Papp L, Vuolteenaho O, Leppäluoto J, DeChâtel R, Ruskoaho H, Tóth M: Involvement of endogenous ouabain-like compound in cardiac hypertrophic process in vivo. Life Sci 2007;80: 1303-1310.

24 Strong KJ, Osicka TM, Comper WD: Urinary-peptide excretion by patients with and volunteers without diabetes. J Lab Clin Med 2005; 145:239-246.

25 Nakayama A, Sakatsume M, Kasama T, Kawara T, Gejyo F, Isobe M, Sato K, Shiba K: Molecular heterogeneity of urinary albumin in glomerulonephritis: comparison of cardiovascular disease with albuminuria. Clin Chim Acta 2009;402:94-101.

26 Gudehithlu KP, Pegoraro AA, Dunea G, Arruda JA, Singh AK: Degradation of albumin by the renal proximal tubule cells and the subsequent fate of its fragments. Kidney Int 2004;65:2113-2122.

27 Markó L, Molnár GA, Wagner Z, Böddi K, Koszegi T, Szabó Z, Matus Z, Szijártó I, Mérei A, Nagy G, Wittmann I: Measurement of the modification and interference rate of urinary albumin detected by size-exclusion HPLC. Physiol Meas 2009;30:1137-1150. 